\title{
Conflitos e indisciplina no contexto escolar: a normatização do Sistema de Proteção Escolar em São Paulo
}

Roberto Alves Gomes a

Angela Maria Martins ${ }^{b}$

\section{Resumo}

Este artigo tem como propósito analisar o programa Sistema de Proteção Escolar - SPE, implementado pela Secretaria de Estado da Educação de São Paulo (SEESP), desde 2011, com foco nos fundamentos políticos e pedagógicos explicitados em seu escopo legal. Apresentam-se, inicialmente, programas e projetos anteriores à implantação do SPE, com vistas a contextualizar medidas e ações no campo da política educacional que incentivavam a participação da comunidade na escola e propunham atividades de prevenção a possíveis situações de conflitos. Na sequência, examina-se o conjunto normativo que regulamenta o SPE, enfatizando as atribuições do Professor Mediador Comunitário - PMC, profissional responsável pela mediação de violência e indisciplina nas unidades da rede estadual de ensino.

Palavras-chave: Política e gestão educacional. Sistema de proteção escolar. Conflitos escolares.

\section{Introdução ${ }^{1}$}

Registre-se, inicialmente, a relevância de se examinar programas governamentais, por meio da análise de seu escopo normativo, pois a pesquisa e a análise

\footnotetext{
a Centro Universitário de Votuporanga - Unifev. Votuporanga, São Paulo, Brasil.

b Universidade Cidade de São Paulo - Unicid, Programa de Pós-graduação em Educação. São Paulo, São Paulo, Brasil.

1 Texto modificado de pesquisa desenvolvida no Programa de Mestrado em Educação da Universidade Cidade de São Paulo, que integra investigação maior coordenada por Angela Maria Martins, financiada pela Fundação Carlos Chagas, intitulada Políticas e Gestão da Educação Básica 2009-2014 - O Estado do Conhecimento. Da referida investigação também participou a aluna Flávia Regina de Melo, da Universidade Cidade de São Paulo, com bolsa de Iniciação Científica do CNPQ desenvolvendo o projeto Órgãos colegiados e equipes de gestão: uma revisão de literatura.
}

Recebido em: 14 mar. 2014

Aceito em: 23 fev. 2015 
documental, conforme explicita Gil (2009), assemelham-se muito à pesquisa bibliográfica, tendo como única diferença, entre ambas, a natureza das fontes. Nas palavras do autor:

Enquanto a pesquisa bibliográfica se utiliza fundamentalmente das contribuições dos diversos autores sobre determinado assunto, a pesquisa documental vale-se de materiais que não receberam ainda tratamento analítico, ou que ainda podem ser reelaborados de acordo com os objetivos da pesquisa (p. 51).

Outro aspecto se refere à importância de se discutir medidas e ações registradas em agendas de governo, articuladas em determinado período histórico, negociadas por entrelaçamentos de interesses no cenário contemporâneo, que amplia a complexidade de entendimento sobre o que o governo faz, para quem e por que, pois coloca em evidência novos atores sociais²: o Estado, que abriga grupos de interesses de funcionários públicos; organizações não governamentais, entidades sindicais e grupos representativos de interesses específicos, tais como os que defendem o direito às diferenças. Assim, as políticas públicas são traduzidas em ações que se realizam em processo, durante o qual negociações são encetadas, e grupos em conflito influenciam a agenda de governo.

Nesse sentido, ressalte-se a importância de realização de estudos no campo das políticas educacionais que buscam centrar seu foco na avaliação de planos, programas e projetos - subárea no campo da análise de políticas contribuindo para ampliar a visão sobre o contexto, no qual são geradas as intenções e ações governamentais ${ }^{3}$.

Dessa forma, tomando por referência a análise documental, por meio da sistematização de conteúdo, foram selecionados os seguintes atos normativos, que orientaram a definição dos pressupostos políticos e pedagógicos do programa Sistema de Proteção Escolar: a Resolução SE no 19, de 12/02/2010 (São Paulo, 2010a); a Instrução Conjunta CENP/DRHU, de 09/04/2010 (São Paulo, 2010b); a Resolução SE no 1, de 20/01/2011 (São Paulo, 2011a); a Instrução Conjunta CENP/DRHU, de 27/01/2011 (São Paulo, 2011b); a Resolução SE no 18, de 28/03/2011 (São Paulo, 2011c); a Resolução SE n ${ }^{\circ}$, de 19/01/2012 (São Paulo, 2012a); os documentos oficiais publicados pela SEESP, em específico o Manual de Normas Gerais e Conduta Escolar (São

2 Ver a discussão realizada por Souza $(2003,2006)$ sobre os teóricos precursores no campo das políticas públicas.

3 Sobre essa discussão, ver Martins (2013). 
Paulo, 2009a) e o Manual de Proteção Escolar e Promoção da Cidadania (São Paulo, 2009b).

\section{Programas e projetos anteriores ao Sistema de Proteção Escolar: a participação da comunidade na escola e prevenção a situações de conflitos}

Entre 1996 e 2010, pode-se dividir os projetos da Secretaria de Estado da Educação de São Paulo (SEESP) voltados ao combate às situações de conflito em dois grupos: no primeiro, os que incentivavam a participação da comunidade na escola e desenvolviam atividades de atenção à saúde, destacando-se o Projeto Comunidade Presente, o Projeto Prevenção Também se Ensina e o Programa Escola da Família. No segundo grupo, encontram-se os projetos que apontavam a necessidade de se incentivar o sentimento de pertencimento da comunidade escolar, indicando um movimento em direção à implementação de ações de prevenção ao uso de drogas, de bebidas alcoólicas e da depredação do ambiente. São eles: o Projeto de Prevenção ao Consumo de Álcool nas Escolas Estaduais e o Projeto Justiça Restaurativa em Heliópolis e Guarulhos: parceria para a cidadania.

A partir de 1996, implanta-se o Projeto Comunidade Presente, cujo objetivo, conforme a SEESP ${ }^{4}$, seria o de capacitar educadores e fornecer instrumentos para que as escolas públicas paulistas pudessem promover a mediação de conflitos, garantindo uma boa convivência e integração com a comunidade, trabalhando estrategicamente com base na participação de todos os atores escolares, fortalecendo valores para contribuir com a diminuição da vulnerabilidade social a que as crianças e jovens estão expostos.

Para Gonçalves e Sposito (2002), o projeto tinha como proposta trabalhar com as unidades escolares, de modo a possibilitar que o espaço público fosse apropriado de maneira saudável pela comunidade. Os autores destacam, ainda, que o projeto tinha a intenção de colaborar com a dinamização das Associações de Pais e Mestres, Conselhos de Escola e Grêmios Estudantis para atuarem na administração dos recursos humanos, físicos e financeiros da escola, com a legitimidade que lhes é conferida. Entretanto, de acordo com os autores, a proposta original não foi implementada efetivamente em todas as suas dimensões, pois as ações de incentivo ao fortalecimento de participação da

\footnotetext{
4 São Paulo (Estado). Secretaria da Educação. Fundação para o Desenvolvimento da Educação. Comunidade presente. Disponível em: <http://www.fde.sp.gov.br/PagesPublic/InternaProgProj. aspx?contextmenu=compresente >. Acesso em: 28 out. 2012.
} 
comunidade se limitaram, em boa parte das escolas da rede, a cumprir um ritual das diretrizes do projeto, configurando-se mais como um processo revestido de caráter burocrático do que, propriamente, como instauração de um espaço aberto e organizado para participação de famílias dos alunos.

No mesmo ano, implantou-se o Projeto Prevenção Também se Ensina que, segundo a SEESP ${ }^{5}$, tinha como objetivo contribuir para a promoção da cidadania e para a redução da vulnerabilidade da comunidade escolar, no que tange à gravidez na adolescência, ao uso indevido de drogas e às DST/Aids (doenças sexualmente transmissíveis/síndrome da imunodeficiência adquirida), elementos que podem potencializar situações de conflito no espaço escolar.

Ações de caráter informativo, com vistas a despertar a conscientização e a formação do jovem por meio de projetos que propiciem posturas preventivas, principalmente em relação ao uso indevido de álcool e das drogas, vêm sendo amplamente discutidas pela literatura da área e pela mídia. Segundo Bouer ${ }^{6}$, o jovem sabe beber, no entanto, não utiliza esta informação na prática, porque não sabe até onde pode ir. De acordo com o autor, no calor de uma festa e no auge da animação, adolescentes são influenciados por amigos e acabam abusando do uso do álcool; assim, um dos aspectos que gera preocupação nos profissionais que trabalham com jovens é a relação entre a diversão e a quantidade de ingestão de bebida alcoólica, o que potencializa situações de violência e conflito.

Após esse projeto, um intervalo de tempo pode ser notado, pois, apenas em 2004, a SEESP ${ }^{7}$ implanta o Programa Escola da Família, com o objetivo de construir, no âmbito da rede de escolas, uma cultura de paz, aprendizagem e recreação. Segundo Chakur e Oliveira $(2005$, p. 8$)$, “o programa não tem como objetivo primordial tratar a violência nas escolas, mas considera sua ação um efeito secundário e também preventivo", pois, por meio da prática de esportes e outras atividades de cunho cultural, busca-se envolver os membros da comunidade no espaço escolar. Entretanto, de acordo com os autores, um dos pontos críticos do Programa parece residir no aspecto socializador das atividades, e não em seu aspecto educativo, como proposto inicialmente no texto

\footnotetext{
5 São Paulo (Estado). Secretaria da Educação. Fundação para o Desenvolvimento da Educação. Prevenção também se ensina. Disponível em: <http://www.fde.sp.gov.br/PagesPublic/InternaProgProj. aspx?contextmenu=prevensina $>$. Acesso em: 28 out. 2012.

6 Bouer, J. Prevenção também se ensina [entrevista]. Disponível em: <www.antidrogas.com.br/mostraentrevista. php?c=68\&msg=Entrevista\%20com\%20Jairo\%20Bouer\%20-\%20Preven\%E7\%E30\%20Tamb\%E9m\%20se\%20 Ensina>. Acesso em: 28 out. 2012.

São Paulo (Estado). Secretaria da Educação. Fundação para o Desenvolvimento da Educação. O Programa Escola da Família. Disponível em: <http://www.escoladafamilia.fde.sp.gov.br/v2/default.html>. Acesso em: 2 nov. 2012.
} 
oficial. Hirakawa e Barros (2007) também apontam problemas ao afirmarem que, apesar de o Programa ter como objetivo levar as famílias para dentro das escolas, essa dinâmica ainda está para ser efetivada, pois as atividades implementadas nos fins de semana são frequentadas efetivamente somente por alunos, em companhia de primos, irmãos e colegas do entorno. Na visão das autoras, o Programa Escola da Família incentiva escolas a assumirem a responsabilidade de crianças e jovens, supondo uma possível ausência de responsabilidade dos pais sobre os (as) filhos (as), o que provoca tensão na atribuição de papéis educacionais e familiares.

A partir de 2006, a SEESP implementou o projeto Justiça e Educação em Heliópolis: parceria para a cidadania, envolvendo algumas escolas da região de Guarulhos e de Heliópolis na capital paulista, processo esse que forneceu elementos para a futura elaboração do Sistema de Proteção Escolar. Segundo o documento oficial, atos violentos podem ser desencadeados por situações anteriores, nas quais a intolerância e a falta de diálogo estiveram presentes. Nessa perspectiva, o projeto apresentou diversas situações de conflito no âmbito escolar, analisadas de diferentes perspectivas (SÃO PAULO, 2007a).

Desenvolvido por meio de parcerias entre a Justiça, a Educação, a Comunidade e o Conselho Tutelar, o projeto fixou, como eixo central, a aprendizagem de procedimentos restaurativos pelos facilitadores voluntários, que iriam operar nos Círculos Restaurativos, nas escolas, no Fórum e na comunidade (SÃO PAULO, 2007a, p. 30). Para isso, a SEESP organizou o Curso de Formação de Lideranças Educacionais, do qual participavam cinco integrantes de cada unidade escolar, junto dos gestores do Sistema Judiciário (Juiz e Promotor).

Gall e Guedes (2009, p. 67), ao analisarem os efeitos do projeto na resolução de conflitos, sublinham que a capacidade de trabalhar em conjunto com outros parceiros é fundamental para que o facilitador encaminhe as dúvidas para outros profissionais, divida responsabilidades e estimule pais e mães mais atuantes a realizarem atividades com as outras famílias de alunos.

Entretanto, o documento oficial aponta que ocorreram resistências no interior das escolas por parte de diretores, coordenadores, professores e funcionários, pois estes assinalavam que a indisciplina não mais seria contida, tendo em vista que apenas o diálogo não resolveria as questões conflituosas, além de provocar a perda de sua autoridade (SÃO PAULO, 2007a). 
Ressalte-se que não é tarefa simples romper com medidas disciplinares consagradas culturalmente nas redes de escolas - e, muitas vezes, legitimadas na família - dinâmica essa que pode acabar apoiando formas de castigo para crianças e jovens, pois muitos dos atores envolvidos podem acreditar que este tipo de disciplina ainda é a mais adequada para a aprendizagem e a manutenção de um ambiente disciplinado.

\section{A legislação do Sistema de Proteção Escolar}

Nesse contexto, o Sistema de Proteção Escolar foi criado em 2009 e implantado oficialmente em 2010, por meio da Resolução SE n 19, de 12/02/2010 (SÃO PAULO, 2010), apontando a necessidade de instaurar, na rede pública de escolas do Estado de São Paulo, ações para prevenir, mediar e resolver conflitos. De acordo com o documento oficial, o Sistema foi implantado de forma descentralizada e gradativa, estabelecendo que, para o atendimento das ações relativas ao Sistema de Proteção Escolar, a SEESP disponibilizaria recursos humanos próprios, cuja contratação levaria em conta fatores de vulnerabilidade e de risco a que estão expostas as escolas da rede estadual de ensino, podendo a unidade escolar contar com até 2 (dois) docentes, para o desempenho das atribuições do Professor Mediador Escolar e Comunitário (PMEC).

Os PMECs foram selecionados pelas Diretorias de Ensino, seguindo algumas prioridades: em primeiro lugar, titular de cargo docente da própria unidade escolar que se encontrasse na condição de adido (sem aula atribuída, cumprindo horário de permanência); em segundo, o docente readaptado ${ }^{8}$ e, por último, docente ocupante da função atividade, abrangidos pelas Disposições Transitórias da LC n ${ }^{\circ}$ 1.010, de 01/06/2007 (SÃO PAULO, 2007b). Com a instituição dessa resolução, ficou também regulamentado o Sistema Eletrônico de Registro de Ocorrências Escolares - ROE, constituindo-se em instrumento de informações on-line para o registro, por parte do Diretor da Unidade Escolar, das ações ou situações de conflito ou indisciplina, danos patrimoniais, furtos, ou ações que possam caracterizar atos infracionais.

Para normatizar os procedimentos de seleção das unidades escolares que passaram a contar com o PMEC, a SEESP publicou uma instrução conjunta CENP/DRHU de 09/04/2010 (SÃO PAULO, 2010b). Os critérios estabelecidos incluíam o preenchimento de uma manifestação de interesse da escola, em contar com o

8 Professor readaptado: professor afastado de suas funções de sala de aula, por motivos de saúde, desenvolvendo outras funções na unidade escolar em conformidade com o rol autorizado pela Comissão de Assuntos de Assistência à Saúde - CAAS. 
docente para exercer as funções de PMEC, a classificação dos candidatos, bem como a atribuição de aulas.

Ao longo do ano de 2010, o docente designado Professor Mediador Escolar e Comunitário colocou em prática o rol de atribuições da função do PMEC, estabelecidas na Resolução SE no 19, de 12/02/2010 (SÃO PAULO, 2010a), caracterizando seu caráter pedagógico: a adoção de práticas de mediação de conflitos no ambiente da escola por meio do diálogo; orientação aos pais; a análise das condições de risco da criança, consideradas prejudiciais para seu desenvolvimento; orientação para que a família utilize-se da rede de proteção social como um mecanismo de segurança; atividades pedagógicas complementares visando à melhoria do processo ensino-aprendizagem. Porém, como é comum ocorrer na implementação de programas de governo, intervenientes de percurso fizeram com que a SEESP, ao analisar os problemas, realizasse ajustes, publicando a Resolução SE n ${ }^{\circ}$ 1, de 20/01/2011 (SÃO PAULO, 2011a), que dispõe sobre o exercício das atribuições de Professor Mediador Escolar e Comunitário do Sistema de Proteção Escolar, alterando o artigo $7^{\circ}$ da Resolução SE no 19, de 12/02/2010 (SÃO PAULO, 2010a), excluindo desse artigo a referência da jornada de 24 horas semanais e a menção referente à manutenção da jornada do professor readaptado.

O novo texto distribuiu, ainda, a normatização da jornada semanal do PMEC, com orientações sobre o enquadramento dos professores. Na Resolução SE $n^{\circ}$ 19/2010 (SÃO PAULO, 2010a), a jornada do professor mediador era de 24 horas e, a partir da Resolução SE no 01/2011 (SÃO PAULO, 2011a), aqueles que tinham jornada superior à de 24 horas passariam a exercer a função em 30 horas semanais, com previsão de até 8 horas mensais, inclusas nesta jornada, para encontros de cunho formativo no núcleo de Gestão Regional do Sistema de Proteção Escolar junto da Diretoria de Ensino. Em continuidade à regulamentação do Sistema de Proteção Escolar, foi publicada a Instrução Conjunta CENP/DRHU, de 27/01/2011 (SÃO PAULO, 2011b), visando à normatização de procedimentos a serem seguidos para recondução de docentes em exercício no ano de 2011, com atribuições de PMEC. Porém, sua avaliação de desempenho deveria ser considerada satisfatória. É preciso ressaltar que as escolas prioritárias (que não conseguiram alcançar a meta estabelecida no IDESP $^{9}$ ) têm prioridade na seleção do PMEC. Já as escolas que não querem contar mais com o PMEC, devem justificar a decisão por meio de um ofício endereçado à Diretoria de Ensino de sua jurisdição. As escolas somente passam a contar com um segundo PMEC, quando funcionam em três turnos, com um mínimo de 10 (dez) classes em cada turno (SÃO PAULO, 2010b).

${ }^{9}$ IDESP: Índice de Desenvolvimento da Educação do Estado de São Paulo. 
A partir desse escopo legal - que regulamentou a implantação do Sistema de Proteção Escolar e possibilitou o desenvolvimento de ações de cunho pedagógico, por meio da função do PMEC ao longo de 2010, 2011 e meados de 2012 - os órgãos centrais da SEESP assinalaram a necessidade de seu fortalecimento e elaboraram os Manuais denominados Normas Gerais de Conduta Escolar (SÃO PAULO, 2009b) e Proteção Escolar e Promoção da Cidadania, conforme se discute a seguir (SÃO PAULO, 2009a).

\section{Documentos de orientação para o funcionamento do Sistema de Proteção Escolar: os Manuais de Conduta e de Proteção Escolar}

Ressalte-se, primeiramente, a relevância de se examinar fundamentos políticos e pedagógicos para identificar as noções que sustentam a ideia de práticas disciplinares no âmbito escolar, com base no Manual de Normas Gerais de Conduta Escolar (SÃO PAULO, 2009b). O referido documento registra que os alunos têm direito a uma educação pública gratuita e de qualidade, sobretudo, tendo em vista que as escolas "abrigam alunos e alunas de diferentes idades, níveis de desenvolvimento psicossocial e estratos sociais, que devem receber do Estado atenções adequadas às suas necessidades" (SÃO PAULO, 2009b, p. 7).

No mesmo sentido, o texto assinala que crianças e adolescentes têm "o direito a tratamento justo e cordial, por todos os integrantes da comunidade escolar". Porém, o documento não se furta a registrar a relação de deveres e responsabilidades, dentre as quais: "frequentar a escola regular e pontualmente, realizando os esforços necessários para progredir nas diversas áreas de sua educação" (SÃO PAULO, 2009b, p. 9). Outro ponto relevante diz respeito às condutas que afetam o ambiente escolar: faltas disciplinares - passíveis de apuração e aplicação de medidas disciplinares - além de condutas que professores ou a direção escolar considerem incompatíveis com "a manutenção de um ambiente escolar sadio ou inapropriadas ao ensino-aprendizagem, sempre considerando, na caracterização da falta, a idade do aluno e a reincidência do ato" (SÃO PAULO, 2009b, p. 10).

O documento oficial sublinha que a ampliação de situações de violência e de conflitos no espaço escolar exige implementação de dinâmicas a serem adotadas pelas equipes gestoras, com vistas a interferir e melhorar as relações interpessoais nas unidades da rede de ensino. Nesse sentido, outro documento oficial foi elaborado e denominado Manual de Proteção Escolar e Promoção da Cidadania. O documento aponta seu objetivo: 
subsidiar a escola pública com aprofundamentos sobre conceitos de direitos civis e constitucionais, além de fornecer informações e esclarecimentos relativos à natureza das atribuições e competências das diversas instâncias a serem mobilizadas no enfrentamento e mediação dos conflitos que comprometem e distorcem a convivência no ambiente escolar e podem até, eventualmente, extrapolar a dimensão pedagógica (SÃO PAULO, 2009a, p. 7).

Organizado em oito eixos centrais, o referido documento baseia-se nos direitos da criança e do adolescente, em conformidade com a Lei Federal no 8.069/1990 (BRASIL, 1990), o Estatuto da Criança e do Adolescente - ECA, assinalando que podem ser apontados dois tipos de violência: a violência interpessoal e a violência coletiva. Nesse sentido, a escola não poderia deixar de abordar o abuso contra a criança e o adolescente - que pode ser caracterizado como negligência, abandono, violência física e violência sexual - expandindo-se, ainda, para a exploração sexual, com destaque para a violência doméstica.

O texto enfatiza a linguagem jurídica e suas definições - o que é crime; contravenção e ato infracional; furto; roubo; calúnia; difamação e injúria - explicitando quais são os crimes e contravenções mais comuns na escola e, principalmente, um tema emergente, o bullying, atrelado a atitudes de preconceito, discriminação e racismo. Finalmente, são abordados os temas da droga e do vício como dependência física ou psicológica de um comportamento ou substância tóxica. Identifica-se um discurso preocupado em subsidiar os gestores das escolas públicas com informações centradas no campo do Direito, com vistas a prepará-los para enfrentar ações de cunho judicial, se for necessário.

O documento prossegue sublinhando as responsabilidades e atribuições de órgãos de governo, com destaque para a Vara Especial da Infância e da Juventude; o Ministério Público, representado pela Promotoria da Infância e da Juventude; o Conselho Estadual dos Direitos da Criança e do Adolescente - CONDECA; o Conselho Municipal dos Direitos da Criança e do Adolescente - CMDCA; o Conselho Tutelar e, finalmente, o Programa de Policiamento Escolar denominado Ronda Escolar.

O referido Manual também estabelece responsabilidades da escola para dirimir ações de conflito: como e quando comunicar aos pais ou responsáveis; quais são as responsabilidades dos professores; a verificação da frequência irregular dos alunos; o acesso às dependências da escola; a aplicabilidade das medidas disciplinares em relação aos alunos e aos funcionários; como tratar os alunos sob 
medida socioeducativa; em quais casos a polícia pode adentrar a escola; quais são os procedimentos para receber um jornalista na escola, dentre outros. O texto assinala ainda que, quando o aluno agredir verbalmente ou fisicamente um colega ou servidor, portar droga, estar alcoolizado na aula, praticar bullying, ter atitudes racistas, depredar o patrimônio escolar, furtar objetos, portar arma e exercer abuso sexual, a direção deverá solicitar a presença da Polícia Militar para que sejam tomadas as devidas providências, e convocar os pais ou responsáveis legais pelo aluno, comunicando a situação ao Conselho Tutelar, se menor de 18 anos.

No que tange a possíveis situações de violência sexual, envolvendo a criança e o adolescente, o Manual indica: de que forma identificar as formas de expressão da violência ou abuso sexual; locais nos quais a violência possa ocorrer; a possibilidade de estabelecer um perfil das vítimas de violência sexual; como proceder quando a escola identifica que a criança ou adolescente está sofrendo o abuso sexual; quais são as consequências imediatas e em longo prazo dos efeitos do abuso; qual deve ser a postura da escola em relação à família quando identifica esse fato; como proceder nos casos de homofobia no âmbito da escola.

De acordo com o documento, a escola deveria aprimorar um olhar observador com vistas a identificar mudanças de comportamento relacionadas à agressividade, ao isolamento, à rejeição ao contato físico. Neste caso, a interferência de caráter pedagógico é ressaltada como a principal alternativa.

Finalmente, ressalte-se que o Manual esclarece dúvidas em relação à importância dos registros visando padronizar as ações do Diretor para providências imediatas, sobretudo, indicando quando ligar para a Polícia Militar, SAMU (Serviço Médico de Atendimento de Urgência), Corpo de Bombeiros, Disque Denúncia e quando o Distrito Policial deve ser procurado. Aponta também motivos pelos quais educadores, mesmo sabendo da obrigatoriedade, não notificam as autoridades sobre suspeitas de ocorrências de violência e abuso sexual. Para trabalhar nesse campo de tensão, o texto sublinha a necessidade de construção de conhecimentos - no âmbito escolar - pautados pela ética, e pela cultura da paz, valores que deveriam compor o Projeto Político Pedagógico das unidades escolares. A ênfase recai sobre a necessidade de processos formativos que incentivem o desenvolvimento de potencialidades de ordem ética, intelectual e afetiva, com vistas à instauração de um clima organizacional nas escolas que propicie maior interação com as famílias dos alunos.

Em suma, as diretrizes expressas no escopo legal e nos documentos oficiais, apresentados anteriormente, buscam regulamentar a gestão das situações de 
conflito, de violência e indisciplina no âmbito escolar, indicando, de forma minuciosa, elementos que possam reorientar práticas de gestores e de professores, subsidiando-os para tratar do tema que logrou centralidade nas políticas educacionais contemporâneas.

\section{Considerações finais}

Inicialmente, alguns programas e projetos implantados pela SEESP foram apontados no período compreendido entre 1996 a 2012, com destaque para aqueles que contribuíram para a discussão sobre as situações de mediação de conflitos escolares, por meio de práticas restaurativas, com vistas a despertar o sentimento de pertencimento da comunidade ao espaço escolar. Ênfase foi dada ao Projeto Justiça Restaurativa em Heliópolis e Guarulhos: parceria para a cidadania, cujo foco está no desempenho do mediador enquanto facilitador das discussões entre os envolvidos no círculo restaurativo, sem se posicionar, articulando os atores escolares para que possam chegar a um acordo lançando mão do diálogo.

Entretanto, também se apontou que esta é uma tarefa complexa para os profissionais da Educação Básica, pois é preciso assinalar que a mudança de concepção, no que diz respeito à mediação de situações de conflito no âmbito escolar - superando formas mais tradicionais de disciplina e castigo para implementar ações baseadas no diálogo -, pode gerar incertezas e fragilidades. De qualquer forma, discutiu-se que o referido projeto - inspirado na justiça restaurativa - configurou elementos e fundamentou princípios para instauração do SPE.

Finalmente, a análise da legislação e dos documentos oficiais que regulamentam o SPE permite apontar avanços no que tange às diretrizes para o encaminhamento de ações na possível resolução de conflitos no espaço escolar. Entretanto, problemas também devem ser apontados.

Alguns fatores dificultaram a contratação do docente para desempenhar a função de Professor Mediador Escolar e Comunitário. Essa dificuldade derivou dos critérios previstos no artigo $3^{\circ}$ da Resolução SE no 1, de 20/01/2011 (SÃO PAULO, 2011a), que estabeleceu uma ordem de prioridade a ser seguida para designação do docente, conforme sua situação funcional. O texto legal promoveu um estrangulamento na contratação do profissional, pois somente depois de esgotadas todas as possibilidades desse docente ter aula atribuída no processo regular de atribuição de aulas no início do ano letivo, lhe é oferecida a "missão" de trabalhar como PMEC, em escolas tidas como mais vulneráveis da rede estadual de ensino de São Paulo. 
Este ordenamento legal a qual o docente candidato a PMEC foi submetido é contraditório, pois, num cenário altamente desafiador que é o universo escolar, promoveu-se a chance para um professor desempenhar essa função como sua única alternativa de "sobrevivência" profissional. Considerando a importância do programa, entende-se que a seleção deste docente deveria ter prioridade de atendimento, pois a função de PMEC é complexa e exige uma atuação que atenda ao cumprimento efetivo do rol estabelecido no artigo $7^{\circ}$ da Resolução SE n ${ }^{\circ}$ 19, de 12/02/2010 (SÃO PAULO, 2010a). Assim, a escolha do docente para atuar como PMEC não poderia ser resultado de "repescagem", da forma que está preconizado na legislação analisada.

Para desempenhar suas funções pedagógicas, conforme apresentadas anteriormente, o PMEC teria que apresentar um perfil profissional compatível, a ser apresentado e discutido no momento de sua contratação, sobretudo, no que diz respeito à capacidade de exercer mediações por meio do diálogo. O exercício da escuta não é tarefa fácil, contudo, instigar a reflexão por meio de atitudes que desencadeiem o protagonismo dos atores escolares em relação aos fatos ocorridos - construindo a atitude de se colocar no lugar do outro - pode levar à construção de uma nova maneira de encarar os conflitos diários no contexto escolar e social.

O estudo também permitiu identificar a existência de dois tipos de orientações: uma primeira, baseada em discurso mais pedagógico e educativo (SÃO PAULO, 2009b); e uma segunda, mais baseada em linguagem da área do Direito (SÃO PAULO, 2009a).

Por orientação do Manual de Normas Gerais de Conduta Escolar (2009b), a Direção da Escola, de imediato, pode aplicar algumas medidas disciplinares de cunho preventivo e repreensivo, sem ouvir inicialmente o Conselho de Escola, podendo tomar medidas que vão desde a advertência verbal à suspensão de até cinco dias das atividades escolares. Chama atenção, também, o Registro de Ocorrência Eletrônica - ROE, que, em conformidade com o inciso IV, $\S 2^{\circ}$ do artigo $9^{\circ}$ da Resolução SE n ${ }^{\circ} 19$, de 12/02/2010 (SÃO PAULO, 2010 ${ }^{\mathrm{a}}$ ), preconiza que "caberá, ao Diretor da Unidade Escolar, a responsabilidade pela inserção e proteção dos dados registrados, podendo, discricionariamente, conceder ao Vice-Diretor e/ou o Secretário de Escola autorização de acesso ao sistema". Ressalte-se que os registros feitos eletronicamente por diretores, vice-diretores e/ou secretários escolares permitem aos órgãos centrais o acesso imediato às situações de segurança das unidades escolares em todo o estado.

No Manual de Proteção Escolar e Promoção da Cidadania (2009a), constata-se que os problemas devem ser identificados e já encaminhados aos órgãos de direito 
de aplicabilidade da legislação, sem se preocupar, de fato, em resolver a situação conflituosa, e contar com a presença e apoio da família para que possam, juntos, família e escola, assumir suas responsabilidades.

É preciso registrar ainda que o programa implementado como política educacional de redução da violência e mediação de conflito escolar poderia configurar um avanço mais significativo como contribuição para o aperfeiçoamento da gestão escolar, caso outras ações fossem adotadas para sua sustentabilidade: elaboração e implementação de ações formativas para crianças, adolescentes e pais, com vistas a apresentar e discutir situações de conflitos escolares, para que juntos - órgãos centrais, escolas e pais - pudessem construir, conjuntamente, possibilidades de superação da violência e da indisciplina; oferta de cursos permanentes voltados ao tema para professores, diretores e coordenadores pedagógicos; instauração de fóruns de discussão sobre situações de conflitos que poderiam ser realizados nas Diretorias de Ensino Regionais de todo o Estado, envolvendo órgãos da justiça, da educação, organizações não governamentais ligadas à área de direitos humanos, e atores escolares.

Uma das principais modificações, entretanto, diz respeito às formas de atribuição de horas para o PMEC, pois a Secretaria de Estado da Educação deveria considerar, como elemento central para seleção, o perfil do docente candidato, por meio de um projeto que seria apresentado e discutido no momento da entrevista com a Comissão de Gestão Regional do Sistema de Proteção Escolar, em nível de Diretoria de Ensino. Ressalte-se, ainda, a prioridade na oferta de formação continuada para o PMEC, com foco no desenvolvimento de competências para mediar conflitos por meio da prática do diálogo, dando sustentabilidade, assim, aos fundamentos identificados no Manual de Proteção Escolar e Promoção da Cidadania, no que diz respeito à necessária formação desse profissional, bem como dos demais profissionais envolvidos na gestão dos conflitos escolares. Senão vejamos.

Em pesquisa realizada sobre o Plano de Formação Continuada de Professores e Gestores (SILVA; MARTINS, 2014), foram identificados ganhos significativos nas ações implementadas pela Escola de Formação de Professores (SÃO PAULO, 2009c), com diretores, coordenadores pedagógicos e professores. Porém, o estudo também constatou inúmeras dificuldades que os atores escolares apresentam na apropriação de conteúdos e metodologias oferecidas nas ações de formação continuada, pois foi possível verificar - em muitas opiniões examinadas - que o referido Plano não toma, como ponto de partida, aspectos cotidianos da escola e/ou não considera a escola como lócus do processo de formação continuada. 
A investigação aponta ainda que, para superar dificuldades teórico-metodológicas e reorientar práticas profissionais, se faz necessário quebrar modelos mais tradicionais de trabalho pedagógico e se lançar a novos desafios, que requer tempo e condições de trabalho adequadas. As ações de formação continuada analisadas no referido estudo - embora relevantes do ponto de vista de atendimento de uma rede extensa ${ }^{10}$ - não contemplam especificamente questões que afetam o cotidiano de trabalho dos atores escolares e/ou as que se referem às situações de conflito no espaço escolar.

Para um Plano de Formação Continuada mais coerente e coeso, seria fundamental que as ações fossem implementadas de forma integrada com outros programas da própria Secretaria de Estado da Educação. No caso em pauta - o Sistema de Proteção Escolar - as atividades teriam que considerar, como ponto de partida, os Registros de Ocorrência Eletrônica (ROEs) para o desenvolvimento de cursos de formação continuada para diretores e PMCs, o que não vem ocorrendo.

10 A Seesp é composta por 5.340 escolas, agrupadas em 91 Diretorias de Ensino; possui 232.193 professores, 6.942 especialistas de suporte pedagógico (dirigentes regionais, supervisores de ensino, diretores de escola e coordenadores pedagógicos), 7.755 vice-diretores, 10.387 professores coordenadores, totalizando 24.479 gestores e 4.900 .000 alunos. 


\title{
Conflict and lack of discipline in the school context: the standardization of the School
}

\begin{abstract}
This article aims to analyze the School Protection System program - SPE implemented by the Secretary of State of Education of São Paulo (SEESP) since 2011, focusing on the political and pedagogical reasons explained in its legal scope. We initially present previous programs and projects to the implementation of the SPE, in order to contextualize measures and actions in the field of educational policy that encouraged community participation in school and that proposed prevention activities to potential conflict situations. Following that, this article examines the normative body that regulates the SPE, emphasizing the duties of the Teacher Community Mediator - PMC, which is the professional responsible for mediating violence and indiscipline cases in the units of state schools.
\end{abstract}

Keywords: Education policy and management. School protection system. School conflicts.

\section{El conflicto y la indisciplina en el contexto educativo: la normalización del sistema de protección de la Escuela en São Paulo}

\section{Resumen}

Este artículo tiene como objetivo analizar el programa del Sistema de Protección Escolar - SPE implementado por la Secretaría de Estado de Educación de São Paulo (SEESP) desde 2011, centrándose em sus motivaciones políticas y pedagógicas. Se presenta inicialmente, programas y proyectos anteriores a la aplicación de la SPE, con el fin de contextualizar las medidas y acciones en el ámbito de la política educativa que fomenta la participación de la comunidad en la escuela y las actividades de prevención propuestas para posibles situaciones de conflicto. Después, se examina el cuerpo normativo que regula la SPE, con énfasis en los deberes del maestro mediador comunitario-PMC, profesional responsable por la mediación de la violencia y la indisciplina de las escuelas estatales.

Palabras clave: La politica y la gestión de la educación. Protección del sistema escolar. Conflictos escolares. 


\section{Referências}

BRASIL. Lei no ${ }^{\text {8.069, de }} 13$ de julho de 1990. Dispõe sobre o Estatuto da Criança e do Adolescente e dá outras providências. Diário Oficial da União, Brasília, DF, 27 set. 1990.

CHAKUR, G. S. L.; OLIVEIRA, M. L. Programas educativos e a violência na escola. In: SIMPÓSIO INTERNACIONAL DE ADOLESCÊNCIA, 1, 2005, São Paulo. Proceedings... Disponível em: $<\mathrm{http}$ ://www.proceedings.scielo.br/scielo.php? pid $=$ MSC0000000082005000200019\&script=sci_arttext $>$. Acesso em: 12 abr. 2014.

GALL, N.; GUEDES, P. M. A reforma educacional de Nova York: possibilidades para ao Brasil. São Paulo: Instituto Fernand Braudel, Fundação Itaú Social, 2009.

GIL, A. C. Métodos e técnicas de pesquisa social. São Paulo: Atlas, 2009.

GONÇALVES, L. A. O.; SPOSITO, M. P. Iniciativas de redução da violência escolar: o caso de São Paulo. In: REUNIÃO ANUAL ANPED, 25., 2002, Caxambu, MG. Anais... Rio de Janeiro: ANPED, 2002. Disponível em: $<$ http://www.anped.org.br/reunioes/25/luizalbertogoncalvest03.rtf $>$. Acesso em: 3 nov. 2012.

HIRAKAWA, A. P. R.; BARROS, I. P. M. B. Programa escola da família: o olhar das crianças sobre o espaço escolar aberto a comunidade. In: ENCONTRO NACIONAL DA ASSOCIAÇÃO BRASILEIRA DE PSICOLOGIA SOCIAL, 15., 2009, Maceió. Anais... Disponível em: $<$ http:// www.abrapso.org.br/siteprincipal/images/Anais_XVENABRAPSO/89.\%20 programa $\% 20$ escola $\% 20 \mathrm{da} \% 20 \mathrm{fam} \% \mathrm{CDlia} . \mathrm{pdf}>$. Acesso em: 2 fev. 2013.

MARTINS, A. M. O campo das políticas públicas de educação: revisão de literatura. Estudos em Avaliação Educacional, São Paulo, v. 24, n. 56, p. 276-99, set./dez. 2013. doi: 10.18222/eae245620132741

SÃO PAULO (Estado). Decreto n ${ }^{\circ} 54.297$, de 5 de maio de 2009. Cria a Escola de Formação e Aperfeiçoamento dos Professores e dá outras providências. Diário Oficial do Estado de São Paulo, 13 maio 2009c, Caderno 1, p. 34.

SÃO PAULO (Estado). Lei Complementar n ${ }^{0} 1.010$, de 1 de junho de 2007. Dispõe sobre a criação da São Paulo Previdência - SPPREV, entidade gestora do Regime Próprio de Previdência dos Servidores Públicos - RPPS e do Regime Próprio de Previdência dos Militares do Estado de São Paulo - RPPM, e dá providências correlatas. Diário Oficial do Estado de São Paulo, 16 jan. 2007b, Caderno 1, p. 71. 
SÃO PAULO (Estado). Secretaria de Estado da Educação. Instrução conjunta CENP/DRHU, de 9 de abril de 2010. São Paulo: CENP/DRHU, 2010b.

. Secretaria de Estado da Educação. Instrução conjunta CENP/ DRHU, de 27 de janeiro de 2011. Dispõe sobre o exercício das atribuições de Professor Mediador Escolar e Comunitário do Sistema de Proteção Escolar na rede estadual de ensino paulista, expedem a presente instrução. São Paulo: CENP/DRHU, $2011 b$.

. Secretaria de Estado da Educação. Justiça e educação em Heliópolis e Guarulhos: parceria para a cidadania. São Paulo: CECIP, 2007a.

. Secretaria de Estado da Educação. Manual de proteção escolar e promoção da cidadania. Sistema de Proteção Escolar. São Paulo: FDE, 2009a.

. Secretaria de Estado da Educação. Normas gerais de conduta escolar. Sistema de Proteção Escolar. São Paulo: FDE, $2009 \mathrm{~b}$.

. Secretaria de Estado da Educação. Resolução SE $n^{\circ} 01$, de 20 de janeiro de 2011. Dispõe sobre o exercício das atribuições de Professor Mediador Escolar e Comunitário do Sistema de proteção Escolar e dá providências correlatas. São Paulo: CENP/DRHU, 2011 .

. Secretaria de Estado da Educação. Resolução SE $n^{\circ} 07$, de 19 de janeiro de 2012. Dispõe sobre o exercício das atribuições do Professor Mediador Escolar e Comunitário do Sistema de Proteção Escolar, e dá outras providências. São Paulo: CENP/DRHU, 2012a.

SÃO PAULO (Estado). Secretaria de Estado da Educação. Resolução SE $n^{\circ} 18$, de 28/03/2011. Altera a Resolução $\mathrm{SE} \mathrm{n}^{\circ} 1$, de 20 de janeiro de 2011, que dispõe sobre o exercício das atribuições de Professor Mediador Escolar e Comunitário do Sistema de Proteção Escolar e dá outras providências. São Paulo: CENP/DRHU, 2011c.

. Secretaria de Estado da Educação. Resolução SE $n^{\circ} 19$, de 12 de fevereiro de 2010. Institui o Sistema de Proteção Escolar na rede estadual de ensino de São Paulo e dá providências correlatas. São Paulo: CENP/DRHU, 2010a.

SILVA, C. M.; MARTINS, A. M. Plano de Formação Continuada de Professores e Gestores: pressupostos e problemas. In: ENCONTRO REGIONAL DA ANPAE - SUDESTE, 9.; ENCONTRO ESTADUAL DA ANPAE-SP , 13., 2014, São Paulo. Gestão de sistemas e de instituições de ensino: políticas e práticas profissionais: anais. Disponível em: $<\mathrm{http} / / \mathrm{www}$. 
youblisher.com/p/1013692-ANAIS-ANPAE-SUDESTE-UNICID-2014>.

Acesso em 20 fev. 2015.

SOUZA, C. "Estado do Campo" da pesquisa em políticas públicas no Brasil. Revista Brasileira de Ciências Sociais, v. 18, n. 51, p. 69-79, fev. 2003. doi: 10.1590/S0102-69092003000100003

. Políticas públicas: uma revisão da literatura. Revista

Sociologia, Porto Alegre, v. 8, n. 16, p. 20-45, jul./dez. 2006.

doi: $10.1590 /$ S1517-45222006000200003

\section{Informações dos autores:}

Roberto Alves Gomes: Mestre em Educação, UNICID. Diretor da Escola EE. José Belúcio, Fernandópolis, São Paulo, Brasil. Professor do UNIFEV. Contato: diretoroberto@hotmail.com

Angela Maria Martins: Doutorado em educação, Universidade Estadual de Campinas - Unicamp. Pesquisadora Senior da Fundação Carlos Chagas e Professora da Unicid. Contato: ange.martins@uol.com.br 